\title{
THE SURGERY OF PEPTIC ULCERATION
}

\author{
H. W. Burge, M.B.E., F.R.C.S. \\ Surgeon, West London Hospital, W.6
}

\section{Duodenal Ulceration}

Until recent times we have had no clear understanding of the etiology of the different kinds of peptic ulceration. Although in medicine an excellent treatment for a disease of unknown cause has often been found by trial and error, yet the best treatment has probably always followed the discovery of its cause.

The use of antacids in the treatment of peptic ulceration must go back very far in the history of medicine. Probably, as with colchicum for gout, the antacids were found to relieve symptoms. However, the knowledge that a high gastric acidity might be important in the etiology of duodenal ulceration seems to date from 1928 , when Chalfen ${ }^{8}$ reported his findings that hyperchlorhydria accompanied the disease.

In the surgical treatment of duodenal ulceration, operations have been used indiscriminately without good reason. Pyloroplasty was used, and discarded, and so too was gastro-jejunostomy. Even gastric resection, which followed gastro-jejunostomy, had its failures until the need to resect at least $70 \%$ of the stomach was understood. This operation today has an anastomotic ulcer rate of some $3 \%$ or more. However, we had learnt by trial and error to remove extensively the acidforming part of the stomach. We had found success in the surgical treatment of duodenal ulceration, but only by extensive removal of an important organ, and this not without mortality, morbidity and, sometimes, disturbing sequelae. All over the world surgeons began to realise the harmful effects that could follow subtotal gastric resection, and no-one could predict which patients would suffer from these symptoms.

From the time of Pavlov and of Edkins it had been known that gastric acid and pepsin secretion was brought about in at least two ways. Pavlov ${ }^{16}$ had clearly shown that the cephalic, nervous or psychic phase of acid secretion was mediated through the vagus nerves and was, to quote his own words, ' completely and forever done away with' by vagal section. Soon after this Edkins ${ }^{11}$ demonstrated the presence of a hormone, which he called gastrin, in the antral mucous membrane, and showed that it caused acid secretion and was formed in response to food in the antrum. This chemical, hormonal, gastric or antral phase is the other important cause of gastric acid secretion.

What is so curious is that no-one until Dragstedt seems to have asked himself the obvious questionif duodenal ulceration is accompanied by a high gastric acidity, then is this acidity the cause of ulceration and, if so, which phase of gastric secietion is increased, cephalic, antral, or both ?

Surgery has lacked the surgeon-physiologist or the physiologist-surgeon. From such a person, in Lester Dragstedt, came the answer to this question. His paper in $1943,{ }^{9}$ showing the high levels of nocturnal acid secretion in two cases of duodenal ulceration, will never be forgotten in the history of gastric surgery, for it marked the birth of a new era. I think we would all agree with him now when he wrote 'I believe that duodenal ulcers are due to a hypersecretion of gastric juice in the empty stomach, dependent upon excessive and abnormal secretory impulses in the vagus nerves. These in turn I believe are in some way aroused by the tensions and strains of modern life'.

If his conclusion is true, then, if Pavlov was right when he claimed that after complete vagal section the cephalic phase of gastric secretion is completely and forever abolished, obviously complete gastric vagotomy must be, at least in the present state of our knowledge, the surgical answer to this disease. It has indeed been unfortunate that, since his brilliant paper in I943, Lester Dragstedt has had to sit by and watch his operation attacked throughout the surgical world. Now, almost 20 years after his original paper, more and more surgeons in every country are coming to believe that complete vagal section combined with a good drainage procedure, by abolishing the cephalic phase of acid secretion, ' completely and forever does away with ' duodenal ulceration.

\section{Incomplete Nerve Section}

Of course this new operation had to be learnt 
and understood. When it was used without gastric drainage, profound gastric retention almost killed the operation, but the addition of gastrojejunostomy soon put this matter right, and longterm studies have proved the lasting results of vagal section. ${ }^{3,4}$ Because the vagal trunks are often multiple, and because surgeons were, in the early years of the operation, unfamiliar with the anatomy of the nerves and the site of operation, a high incidence of incomplete nerve section occurred. Indeed, not infrequently the main vagus trunks were overlooked. Stempien and Weinberg, ${ }^{19}$ in their paper on recurrent ulceration after vagotomy, described I I cases in which further operation had been undertaken. The main right vagus trunk was found intact in six cases, and the left in one. In one case a small intact nerve was found. In two cases adhesions prevented a search for nerves, and in only one case was no intact nerve found. Perhaps today, with the electrical stimulation test, an intact nerve could have been found in this case too. There is evidence that a small nerve can produce considerable acid, and incomplete nerve section therefore was the cause of recurrent ulceration. The Hollander insulin test meal, which could be used only after operation, showed how often incomplete nerve section was done. The introduction of the electrical stimulation test for complete nerve section, which could be used during operation, ${ }^{6}$ means that the surgeon can now guarantee his patient complete nerve section, whereas before, the operation was very much hit-and-miss and success was left to chance. It is true that surgeons much experienced in vagotomy will seldom overlook small nerve trunks and never, perhaps, large nerve trunks, but even they cannot guarantee complete section without test. Less experienced surgeons most certainly need a test if the operation is to be done properly.

\section{Post-Vagotomy Diarrhoea}

Even with recurrent ulceration abolished by proved complete section during operation, and the symptoms of gastric retention abolished by gastro-enterostomy, there still remains the unpleasant complication of diarrhoea which follows total abdominal vagal section.

Post-vagotomy diarrhoea is troublesome and not uncommon, though seldom severe. Some surgeons have been unaware of this complication, and yet we have found the same incidence in cases drawn from different cities in this country. A study of the incidence and severity shows these almost unchanged ten years after operation. Some $30 \%$ of patients still have this symptom. The incidence and severity seem much the same when pyloroplasty is used rather than gastro- enterostomy. ${ }^{5}$ Table I shows the replies to questions in a typical case of diarrhoea ten years after operation.

\section{TABLE I}

Do you still have diarrhoea?

If so, does it date from your stomach operation?

How often do you have diarrhoea?

(Please state whether daily, weekly or monthly.)

Do the motions become buffcoloured and/or liquid when you have diarrhoea?

How many motions per day would you have with diarrhoea attacks ?

What colour are the motions when you have diarrhoea ? (Buff, yellow, light brown or brown.) What colour are the motions in
the absence of diarrhoea ? (Buff, yellow, light brown or brown.)

Does the diarrhoea cause any urgency?

Are you disabled by these symptoms?

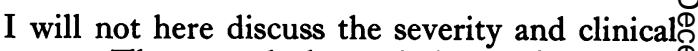
picture. These, and the technique of selective 3 vagotomy, used to prevent post-operative diatrhoea, have already been published. ${ }^{3}$ Since that ${ }^{-}$ paper was written, more cases of bilateral selectipe vagotomy have been added, and the histogra (Fig. I) gives the up-to-date figures from the West? London Hospital. I think we must conclude now that bilateral selective vagotomy, by preserving the vagal innervation of the biliary system, the liver, the pancreas, and the small gut, prevents $\stackrel{\circ}{\varnothing}$ post-vagotomy diarrhoea and retains the normal $\vec{\overrightarrow{ }}$ colour of the motions. It is interesting to note $\frac{3}{3}$ that the preservation of the hepatic branch of the anterior nerve seems to play a more important role than the coeliac division of the posterior.

If our conclusions about selective vagotomy are true, then a whole new field of physiological study is opened up, and the role of the vagus in hepatic, biliary and pancreatic function will need further 0 study. We know that the hormonal phase of gastric acid secretion does not function properly을 when the vagus is divided. Could then the $\rightarrow$ hormonal phase of pancreatic, hepatic and biliary function also be partially dependent on intact vagus nerves? It is interesting to read the words of Carlson ${ }^{7}-$ As regards the intrinsic nerve control $N$ of the contraction of the gall bladder, and the musculature of the bile passages, and particularly the sphincter of Oddi, there are few fields in 0 experimental physiology in which so much serious work has been done with so few conclusive results'. ? Nearly 20 years later we find Johnson and Boyden ${ }^{13} T$ 
INCIDENCE OF

POST-VACOTOMY DIARRHOEA

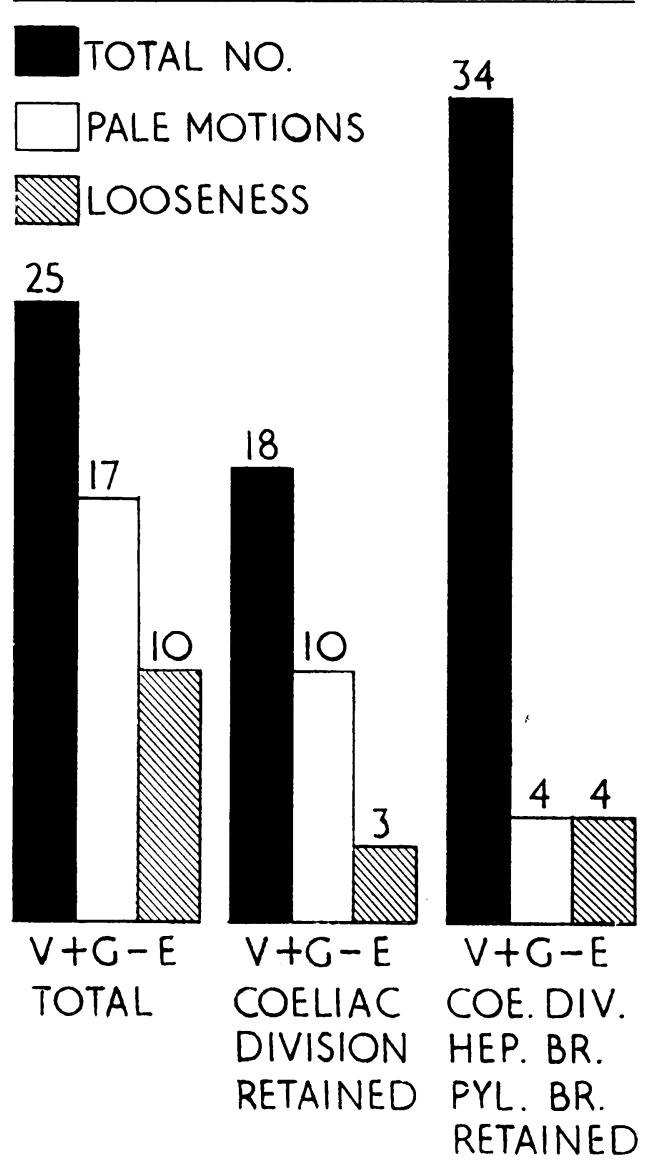

Fig. I disease, which tends so often to be one of healing and relapse. If surgery then becomes indicated, often the surgeon is wise to use this natural history and to perform the operation when the ulcer is healed. 'This principle becomes important when the surgeon is confronted with a patient having a very large gastric ulcer on the mid-lesser curve. 'This, above all, is the type of case in which healing should, if possible, be allowed to occur before operation is undertaken. Then the operation, technically, is easier and complications less liable to occur. It seems that no matter how low the gastrectomy performed for gastric ulceration, the anastomotic ulcer rate is nil, or very nearly so. Very few surgeons probably have ever seen anastomotic ulcer after gastrectomy for gastric ulcer. This surely must mean that even a low gastrectomy - nothing more than antrectomy--is required to cure recurrent gastric ulceration. This interesting conclusion, derived from consideration of the past history of gastric ulcer, may, as will be discussed later, have an important bearing on some recent claims in the etiology of this disease. Most surgeons would agree that the operation of choice is a gastrectomy by the Billroth I technique.

\section{The Very High Gastric Ulcer}

If an ulcer is placed very high on the lesser gastric curve (Fig. 2), a very high gastrectomy would be necessary if the Polya type of operation were used. Some surgeons use Pauchet's procedure. The ulcer is excised and a new lesser curve made. Fig. 3 is taken from Pauchet's original description. In such a high ulcer the stomach wall is oedematous and unpleasant to handle, often as high as the gastric cardia. Pauchet did not discuss the morbidity or mortality of his technique, but my experience, and the experience of other surgeons, has led me to believe that complications, such as sub-phrenic abscess and chest complications, are liable to occur if resection of a high ulcer is done in this way. The Billroth I method too, for a high ulcer, requires a similar technique.

Such a high ulcer, like the large one on the midlesser curve, is best allowed to heal, when a low gastrectomy is performed. Sometimes these high ulcers refuse to heal and perhaps malignancy is suspected. This problem is not a new one in the history of gastric surgery and was faced by surgeons many years ago. Madlener, and others of his time, in such cases performed a gastrectomy below the high ulcer, and reported good results. The author for some years has used this method, and it is one which is now not uncommonly advocated in the world of gastric surgery. It seems that a low gastrectomy will, for all time, cure longstanding high gastric ulceration. To remove

\section{Gastric Ulceration}

Indications for Surgery

If a gastric ulcer is known to be simple, then the indications for operation, as in duodenal ulceration, are--a long history of recurrent trouble and considerable disability over that time. 'The problem is not to heal the ulcer, for time alone will do this according to the natural history of the 


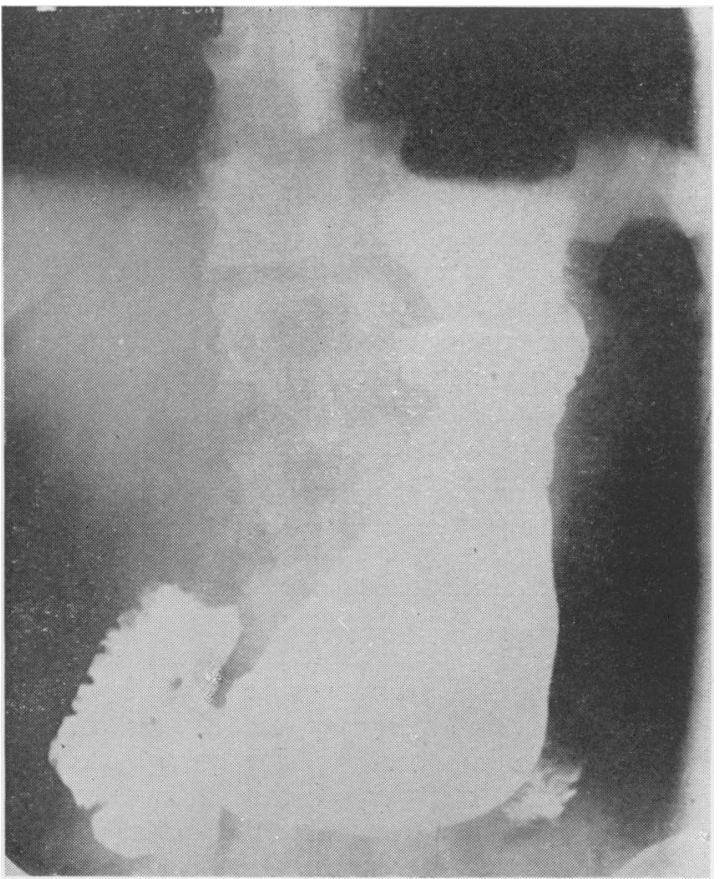

FIG. 2

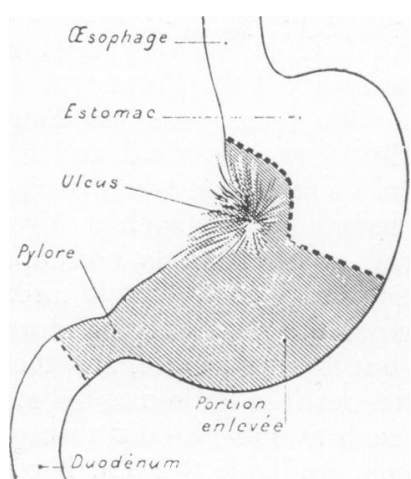

FIG. 3 (see text)

such a high ulcer will, in many cases, require almost total, or even total, gastrectomy. This must never be done if a low gastrectomy will cure the lesion without risk. If necessary, a biopsy of the ulcer to exclude malignancy may be taken at the time of operation.

\section{The Diagnosis of Simple from Malignant Ulceration of the Mid-Gastric Curve}

The diagnosis of simple from malignant ulceration is still one of the most difficult and important problems in gastric surgery. Sometimes, with the abdomen open, and with the stomach itself open, the surgeon finds it difficult to decide whether a lesion is simple or malignant. It

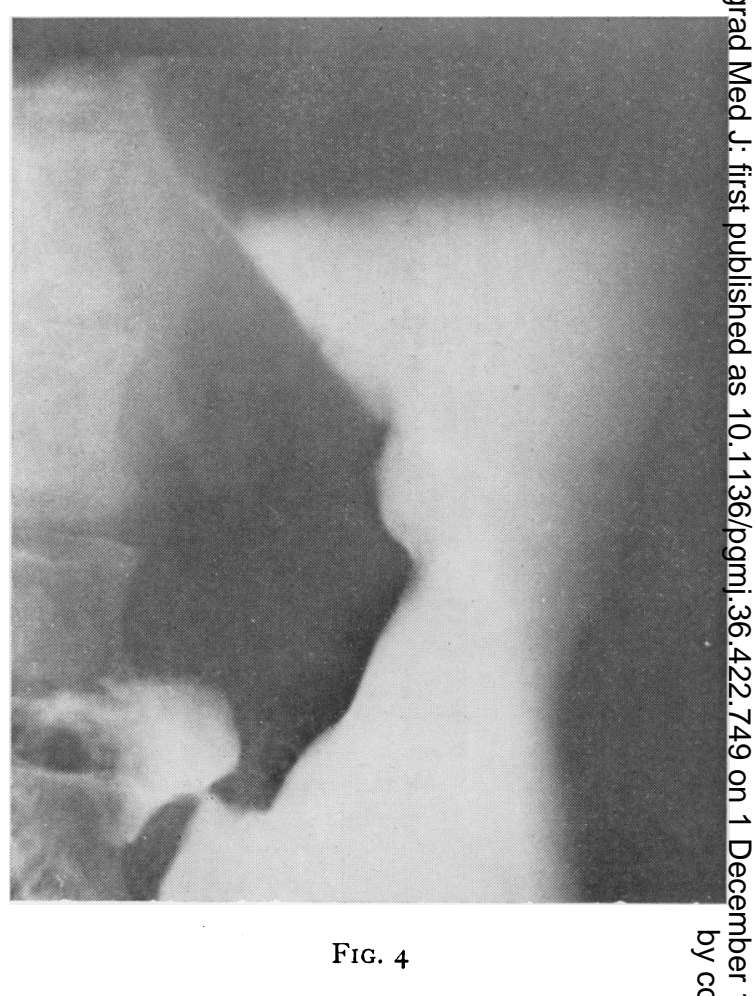

is understandable therefore that gastroscopy ho $\frac{0}{6}$ not proved a very reliable investigation. In ulces at this site radiology and clinical acumen must play the most important roles. In simple ulceration the ulcer crater in the maximal profile view is seen in the X-ray to project beyond the lesser curve, $\stackrel{2}{\circ}$ and this is true even for small ulcers. Malignant $\propto$ ulcers seem to be shallow, and the crater seems to $\vec{\overrightarrow{ }}$ lie within what one might call the basic barium 3 line of the lesser curve (Fig. 4). The lesion takes? on the appearance of a large shallow ulcer, the edges of which present as filling defects in the음 barium picture, and it is these edges which are responsible for the intra-luminal meniscus sign $\frac{5}{3}$ which lies deeply within the stomach, so characteristic of malignant ulceration (Fig. 5). The patient whose X-ray is shown in Fig. 4 was a

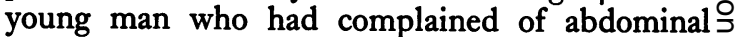
pain after food for two years, and who had been $D$ diagnosed on purely clinical grounds as a case of simple ulceration. When seen after this time he N was apparently very well, and would have been considered clinically as a case of simple ulcer. 은 However, to the radiologist the ulcer with its intra- $\omega$ luminal meniscus must be diagnosed as malignant.

\section{Pre-Pyloric Ulcer}

Although the differential diagnosis of simple $\stackrel{\text { P }}{+}$ from malignant lesions of the mid and upper lesser $\frac{7}{0}$ curve is often not too difficult, this is not true of $\frac{\mathrm{D}}{\mathbb{\mathrm { D }}}$ 


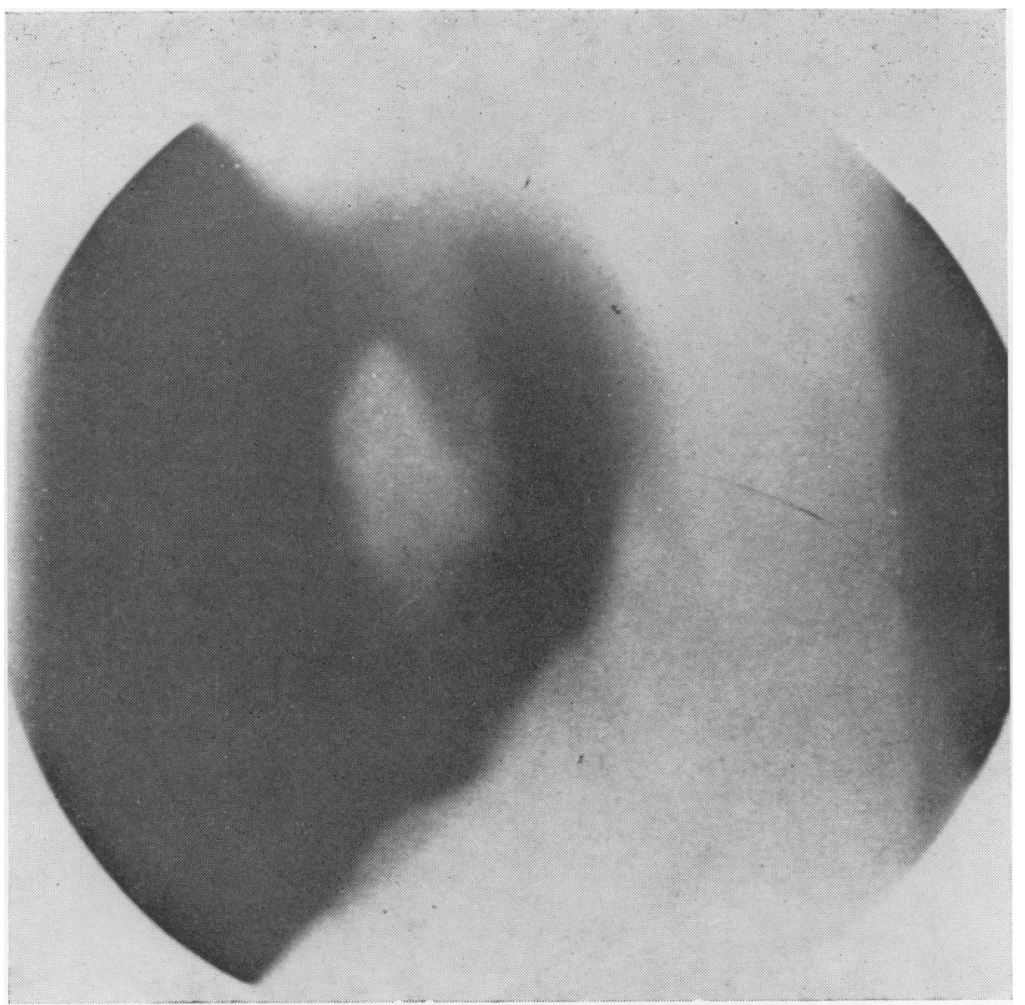

FIG. 5

lesions of the pre-pyloric region. Until recently no advance has been made in the radiological diagnosis of simple from malignant lesions of this site. It is often said that laparotomy should be undertaken to make certain of the diagnosis, but having got this far most surgeons would proceed to gastrectomy whether they thought the lesion was simple or malignant. There is no doubt that very great changes are taking place in radiological methods, and image intensification and cine radiography, and especially television, offer something new in diagnosis of this region. Clinician and radiologist can now together watch function, and this is a very great advance on looking at a single film. Barium may be seen flowing over a persistent defect, sometimes in carcinoma, and the antrum may be shown to be free from a filling defect and to have good mobile walls in simple antral lesions. Pre-pyloric lesions may still be difficult, but are less difficult than they were, and radiology and gastroscopy are now two important investigations. Again, to wait a few weeks is not harmful in malignant disease, and a little time with further investigation may be of the utmost value.

\section{Exfoliative Cytology}

The recognition of exfoliated malignant cells in uterine cancer has become a standard and important method of diagnosis, and routine smears during gynaecological examination are widely used in the United States of America and, less so, in this country. Probably the accuracy of this method depends upon the great experience of a skilled cytologist. Reports on gastric exfoliative cytology too have been more encouraging from North America than from England. The figures rereported by Ratkin, Kirsner and Palmer ${ }^{18}$ from Chicago are interesting.

TABLE 2

Exfoliative Cytology (Total Cases 501)

\begin{tabular}{c|c|c|c}
\hline $\begin{array}{c}\text { Proved } \\
\text { Benign }\end{array}$ & Negative & $\begin{array}{c}\text { False } \\
\text { Positive }\end{array}$ & Accuracy \\
\hline 403 & 400 & 3 & $99 \%$ \\
\hline $\begin{array}{c}\text { Proved } \\
\text { Malignant }\end{array}$ & Positive & $\begin{array}{c}\text { False } \\
\text { Negative }\end{array}$ & Accuracy \\
\hline 98 & 93 & 5 & $95 \%$ \\
\hline
\end{tabular}

(Ratkin, Kirsner and Palmer, Chicago ${ }^{18}$ ) 


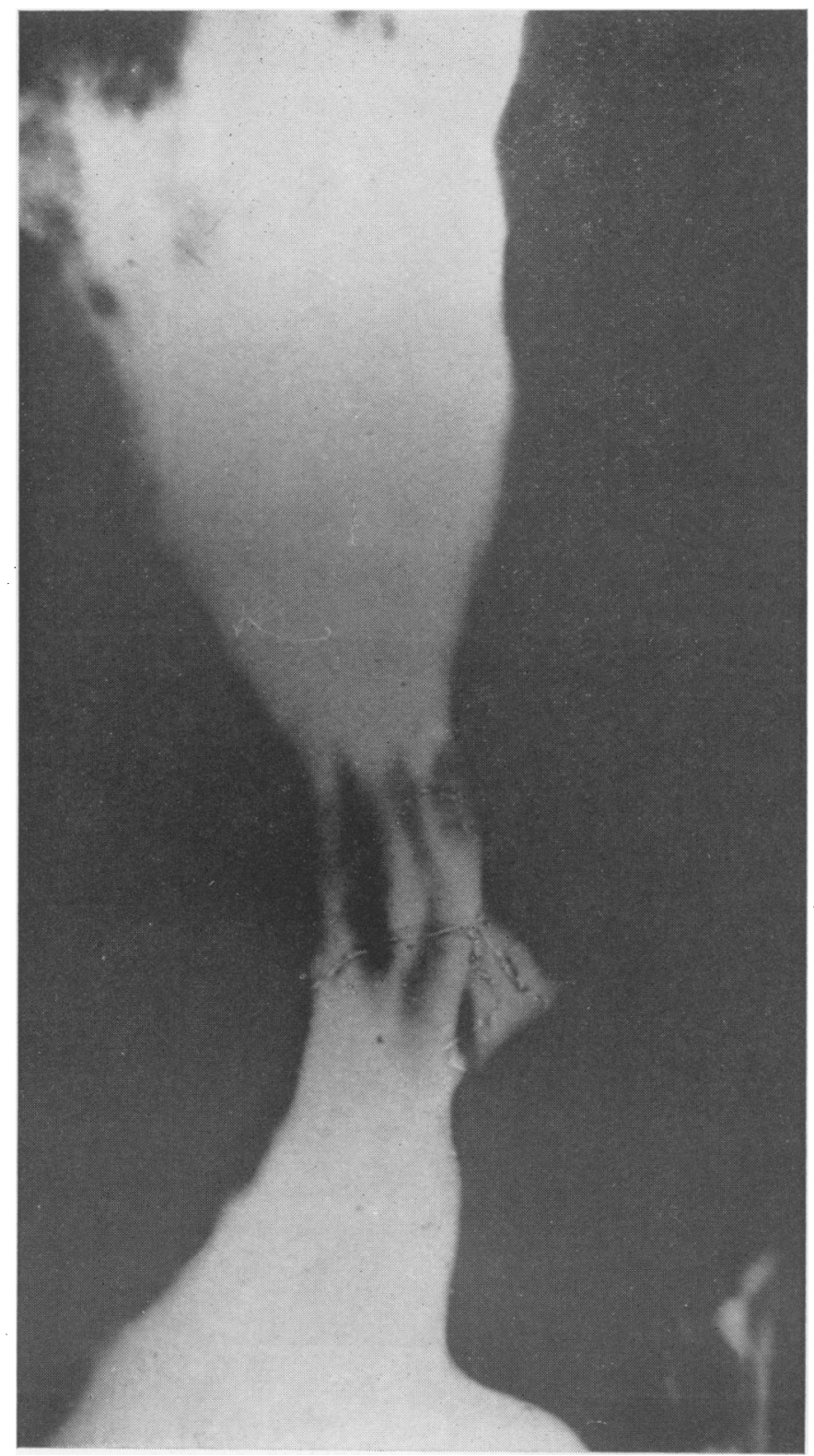

Fig. 6

It may be that there is some need in this country to set up facilities, within regions, for such cytological examinations, to cover different branches of pathology. Landor ${ }^{14}$ states that the method has given a $95 \%$ accuracy in all gastric lesions, but that in our most difficult problem, the small maligntant gastric ulcer, malignant cells were found in only seven of 17 cases.

\section{Ulcer Cancer}

For many years surgeons have discussed, argued and worried about the risks of malignant change being present in simple gastric ulcers. N Some have claimed that simple gastric ulceration is a pre-cancerous condition and that gastrectomy 0 must be undertaken for it. The general opinion $\omega$ today is that our problem is one of the differential diagnosis of simple ulcer from primary malignant 0 ulcer. However, there is little doubt that some $\mathbb{\Phi}$ simple ulcers do become malignant, just as do $\stackrel{\mathscr{P}}{+}$ varicose ulcers. As with varicose ulceration; so $\frac{T}{0}$ with gastric ulceration, this change probably $\frac{\vec{D}}{\mathbb{D}}$ 


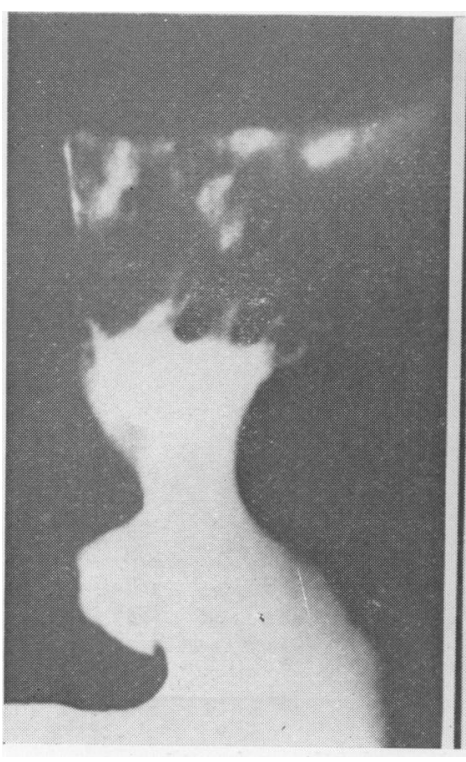

FIG. 7

occurs only when ulceration has been longstanding over many years. Fig. 6 shows an X-ray of a patient with a long history of simple ulceration. Fig. 7, taken many years later, is of the same patient with a large penetrating simple ulcer flattened by pancreatic involvement. At the top edge of the oedematous margin an irregularity is seen, which proved to be a malignant area. However, this problem of malignant change in longstanding chronic ulceration should not arise, for simple ulcers should not be allowed to have such a long chronic history before surgery is undertaken.

\section{The Simple Penetrating Gastric Ulcer}

The term ' free ulcer' may be used to imply one which has not made contact with a solid viscus. The edge of such an ulcer is rounded. The term ' penetrating ulcer' implies one which has involved a solid viscus, usually the pancreas. However, the pancreas itself does not ulcerate, but forms the base of the gastric ulcer, which appears therefore flattened at its apex. As this state of affairs progresses the body of the pancreas comes to lie closer to, and then on, and later within, the basic barium line of the lesser curve, until it develops the very characteristic contour seen in Fig. 8. The tell-tale spasm of the greater curve is so often present. The importance of this ulcer is that, because it has the appearance of a filling defect, it is not infrequently reported as malignant. Indeed it has, like carcinoma, a filling defect, but the defect is the body of the pancreas lying within

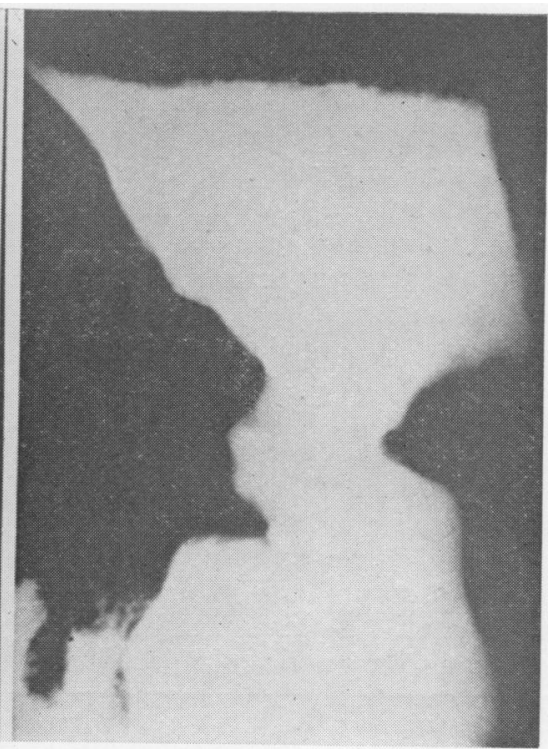

FIG. 8

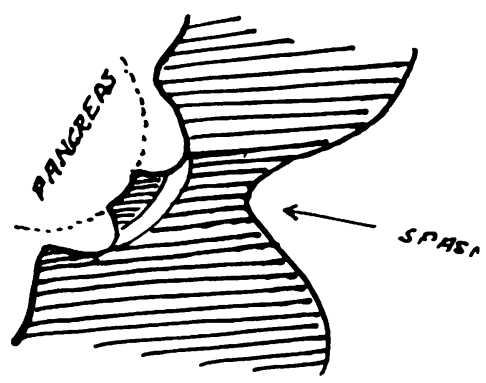

FIG. 9

the gastric contour and augmented by great oedema of the ulcer margin (Fig. 9). If this lesion is mistakenly regarded as malignant, then a very high gastrectomy may be undertaken, whereas with time such an ulcer would probably always heal, and then only if the history is long should surgery be undertaken and a low gastrectomy performed. It will be noted how very similar the contour line of this case is to that in Fig. 7, where malignant change has taken place in the upper margin of the ulcer.

\section{Gastric Ulcer-A New Concept}

Gastrectomy for duodenal ulcer found its place in surgery by trial and error before any clear idea of its etiology was known. As soon as it was understood that this ulceration was caused by an over-active psychic phase of acid secretion, then a new and better operation-vagotomy-was born. 
So too, low gastrectomy for gastric ulcer developed by trial and error, while the cause of gastric ulceration remained unknown. Might not then some similar advance take place if the cause of gastric ulcer became apparent ? Madlener found by trial and error and without, it seems, good reason, that low gastrectomy below an ulcer would cure it. If it is true that surgeons never see recurrent ulceration after gastrectomy for gastric ulcer, no matter how low resection is done, we might fairly conclude that nothing more than antrectomy is necessary. If this is so, we should conclude that the cause of gastric ulcer lies in the gastric antrum. What function then, of the gastric antrum, causes ulceration? Apart from its motility, the only function of the antrum that we know something about is its property of forming the hormone gastrin from its mucous membrane and producing, in so doing, the gastric hormonal or antral phase of gastric secretion. This hormone is formed in response to distension, and to food in contact with the antral mucosa. If food is retained for an abnormal length of time, then the antral phase of secretion will be increased and prolonged. We know that delayed gastric emptying after total abdominal vagotomy without gastric drainage may result in gastric ulceration, and that a gastro-enterostomy stoma too highly placed in the stomach, especially in the presence of duodenal stenosis, may lead to recurrent ulceration. We know too that the retained antrum in Finsterer's gastrectomy with exclusion, by virtue of its retained antral mucosa, causes a high recurrence rate of anastomotic ulceration. In recent times Dragstedt and his co-workers in Chicago have brought forward an intriguing hypothesis. It was in Chicago, and from Dragstedt, that vagotomy was given to the world. It was there that Dragstedt conceived the importance of the psychic phase of secretion in duodenal ulcer. Have the same men, from the same centre, given us a new and better understanding of gastric ulcer too ? They claim $^{15}$ that if a special barium meal is given, then in the majority of patients with simple gastric ulcer, and without organic obstruction of the pylorus, 'significantly lengthy emptying times' are found. They claim too that during this time the gastric acidity is increased. This interesting hypothesis would certainly explain why low gastrectomy cures even high ulcers. Although this work needs yet to be confirmed, we have here fresh food for thought and a new opportunity for study. Dragstedt's work knocked out of the muddle of our thinking and practice a pathology in duodenal ulcer based on disordered physiology. Perhaps this will be true also for gastric ulceration. We owe this man more than he can ever know.

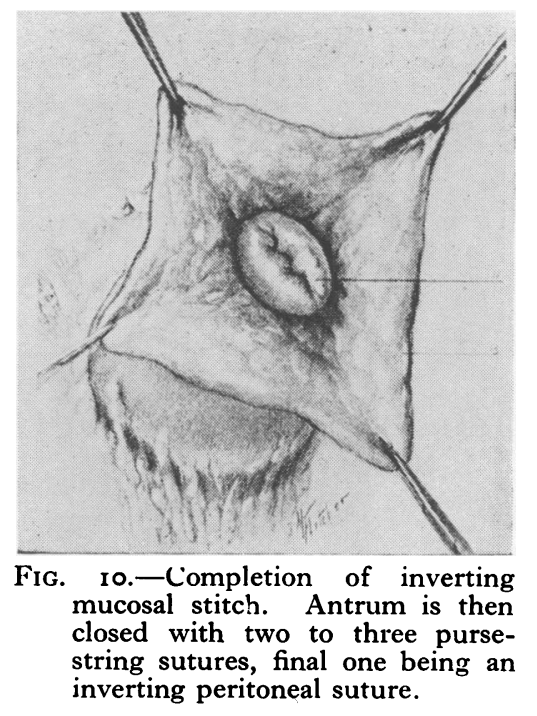

\section{Stomal Ulcer after Gastrectomy}

Perhaps the importance of vagotomy in duo-을 denal ulcer was brought home to many surgeonsbecause of the wonderful results of vagal section in stomal ulcer after gastrectomy. Little need be said now on this subject for it seems that, except? when stomal ulcer is produced by an endocrine cause, as in the Zollinger-Ellison syndrome, complete vagal section is curative. It is remarkabse. with what rapidity large and chronic ulcers wi. heal. Such ulcers are often completely healed within two weeks. For some time surgeons thought that resection of the ulcer, with the for-言 mation of a new stoma, should be combined with the vagal section. This was based on ideas that $\stackrel{\square}{\circ}$ the healed ulcer might be more prone to break $\overrightarrow{\overrightarrow{0}}$ down. This thinking does not conform to 3 surgical principles, for if the cause is removed the ulcer must be cured and remain so. Also, it has? been shown that there is no need to touch theo ulcer, no matter how large or how chronic it may be. It was thought too that anastomotic ulcer $\frac{0}{3}$ after inadequate gastric resection should be treated by vagotomy plus a high gastrectomy. Vagotomy with gastro-enterostomy cures duodenal ulceration, and therefore there can be no reason for making a low gastrectomy into a higher one. $\frac{D}{0}$ Nothing more is required than vagal section, even though the gastrectomy is low. Sometimes we see N cases in which stomal ulcer has followed Finsterer's gastrectomy with exclusion, where the gastric $\mathcal{N}$ antrum is retained. Perhaps it is more com- $-\mathrm{W}$ monly seen today when this operation has been done with ablation of the antral mucous membrane. 0 Such ablation is usually not total, for it is not $\mathbb{\complement}$ generally carried through the pyloric ring, and a small amount of gastric mucous membrane is $\frac{0}{0}$ 
TABLE 3

INCIDENCE OF ANASTOMOTIC ULCERATION

\begin{tabular}{|c|c|c|c|c|}
\hline & No. & Time & $\begin{array}{l}\text { Inci- } \\
\text { dence }\end{array}$ & \\
\hline $\begin{array}{l}\text { I. With Retained Ant- } \\
\text { rum } \ldots\end{array}$ & 9 & $?$ & $55 \%$ & $\begin{array}{l}\text { Allen \& } \\
\text { Welch }\end{array}$ \\
\hline 2. With Ablation & 68 & $3 \mathrm{yr}$. & $7 \%$ & Burge \\
\hline Duodenal Closure. & 200 & $5 \mathrm{yr}$. & $2 \%$ & Burge \\
\hline
\end{tabular}

retained. It is clear from Bancroft's original pictures (Fig. 10) that this was in fact how he performed the operation. It has been shown ${ }^{2}$ by the author that even this small amount of retained gastric mucosa may cause, through its hormonal secretion, anastomotic ulceration (Table 3). Vagotomy appears to cure stomal ulceration when these conditions exist.

\section{Stomal Ulcer after Gastro-Enterostomy}

As early as 1930 Berg $^{1}$ reported that gastroenterostomy alone in the treatment of duodenal ulceration carried a recurrence rate of some $30 \%$, and this figure-or an even higher one-is now regarded as true. In the rg20s and r 930 s in England some surgeons thought that the recurrence rate from this operation was low, and because of this it enjoyed a long but unwarranted popularity. Even today we are sometimes, though rarely, seeing stomal ulcer after gastro-jejunostomy. The place of vagotomy alone for this type of stomal ulcer needs careful consideration, for there is one important aspect of this lesion not present when stomal ulcer follows gastrectomy. The gastric antrum is retained, and if duodenal stenosis is present, and if the gastro-enterostomy stoma is too highly placed, then the antral or humoral phase of acid secretion may be augmented and play an important part in the production of stomal ulcer, as it does in gastrectomy with exclusion. This fact probably accounts for the less certain results of vagal section in this condition. Relatively little has been written about the results of vagotomy for stomal ulcer after gastro-enterostomy, and of course some bad results must be due to incomplete vagal section. It does seem that the variable results are probably accounted for by the difference between those cases in which gastroenterostomy is well performed, with a low stoma, in which the stomal ulcer is caused by the cephalic phase of secretion, and those in which the stoma is too highly placed, when the antral phase plays a predominant part. In the first place vagotomy alone will heal the ulcer, and in the second vagotomy should be combined with antrectomy.

\section{CASE I.-Mrs. N. P., aged 52.}

This patient began her symptoms of duodenal ulcer

\section{BEFORE OPERATION}

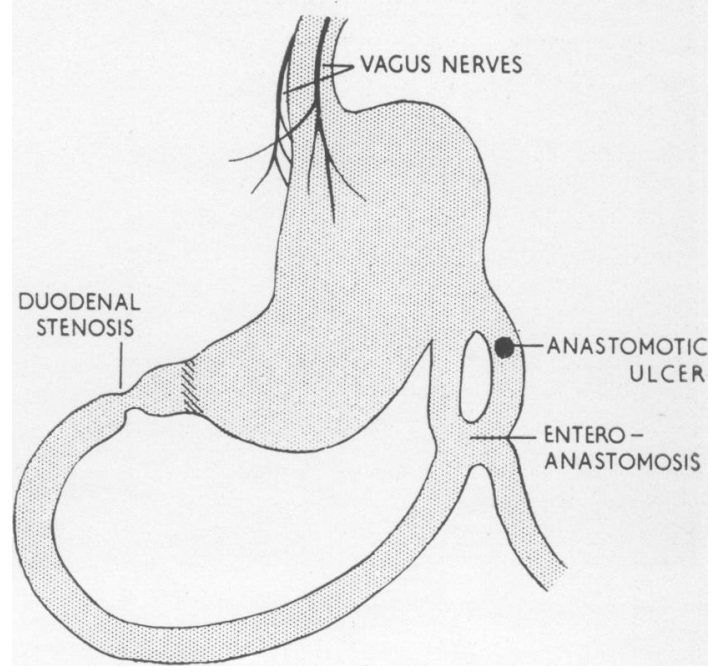

FIG. I I

\section{AFTER OPERATION}

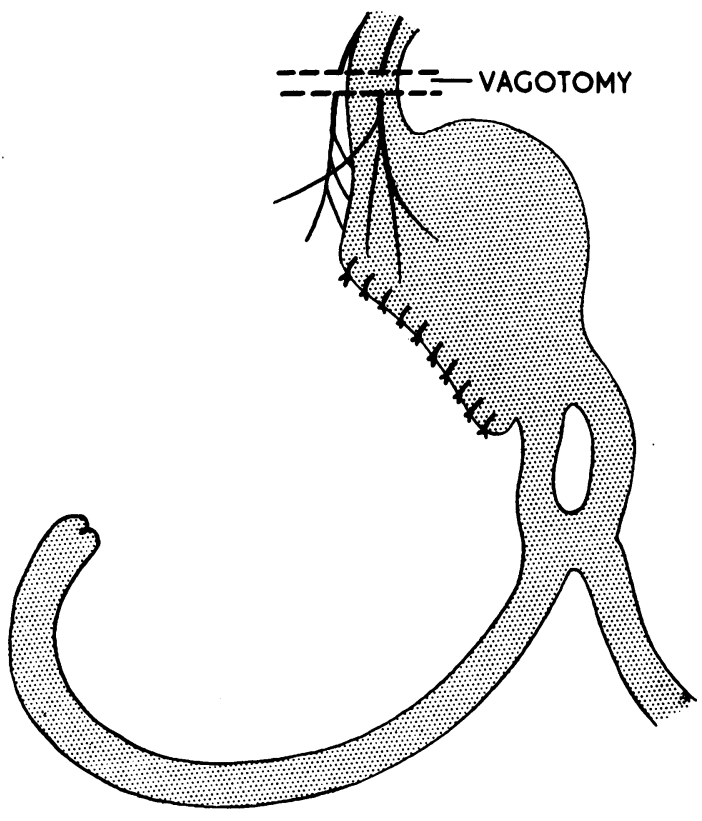

Fig. 12

at 18 years of age, in 1915. In 1936 a gastroenterostomy was performed for severe duodenal stenosis. This was followed by an entero-anastomosis and many years of recurrent trouble. In 1949 she was found, on $\mathrm{X}$-ray examination, to have severe duodenal stenosis, a very high gastro-enterostomy stoma, an entero-anastomosis, and an anastomotic ulcer distal to the short- 


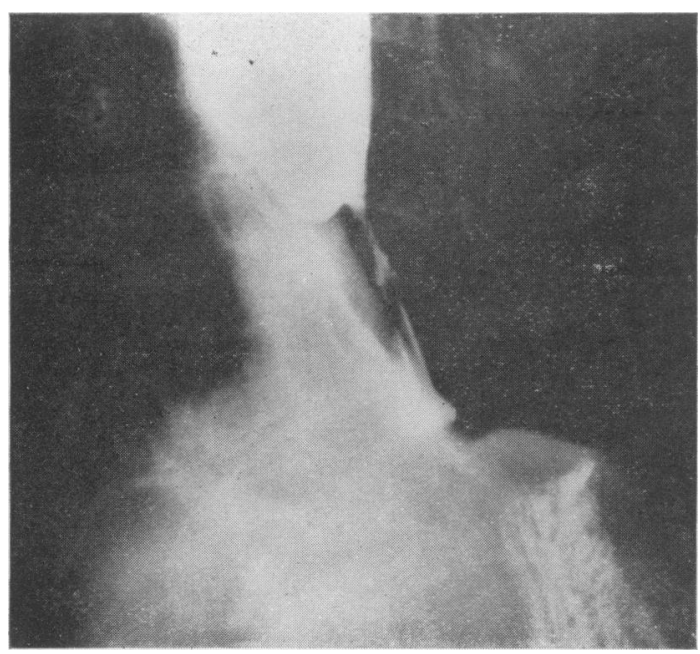

FIG. 13

circuit opening (Fig. II). These findings were confirmed at operation. The stomach beyond the gastroenterostomy stoma was excised and a bilateral vagotomy performed. The stoma itself, and the entero-anastomosis and the anastomotic ulcer, were not disturbed (Fig. 12). This patient is now well and has had no symptoms of gastric trouble since this operation 12 years ago.

\section{Oesophageal Ulcer}

It is surprising that so little has been written about the place of vagotomy and gastro-enterostomy in the treatment of peptic oesophagitis with its complications of peptic ulcer and peptic stricture. All these conditions arise from the reflux of gastric juice through the cardia, usually cases of hiatus hernia. In $195^{\circ}$ Dragstedt and Woodward ${ }^{10}$ reported the results of vagotomy for peptic ulcer after seven years, and mentioned its use in ' certain oesophageal ulcers'. They stated that they had encountered two patients with duodenal ulcers, and simultaneous ulcers in the lower oesophagus, and that the lower oesophageal ulcers healed after vagotomy with subsequent organic obstruction. Wangensteen, ${ }^{20}$ in 1959, reported the beneficial effect of subtotal gastrectomy of the Polya type in the treatment of simple peptic stricture. It seemed that by removing a large part of the acid-forming stomach, and because of the free gastric drainage after gastrectomy, acid reflux was diminished and conconsiderable improvement of the stricture resulted. Such strictures are so often narrow, not so much from fibrosis as from oedema and spasm, and it is remarkable what very great improvement occurs even in what appear to be severe cases when the cause is removed. Total gastrectomy, with oesophago-jejunal anastomosis and excision of the

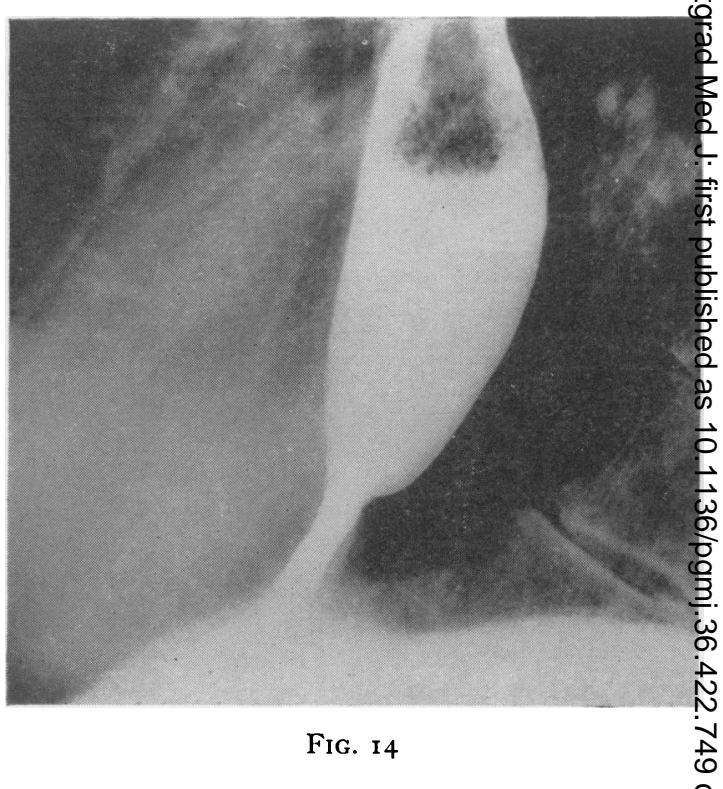

stricture, seems to be too big an operation, and to을

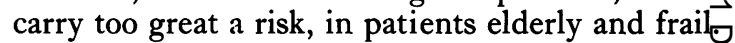
Certainly such an operation must be unwise if good result can be obtained without sacrificing ans stomach at all.

CASE 2.-Miss H. G., aged 65 .

After many years of heartburn and dyspepsia patient was unable to eat solid food. She had much weight, and the X-ray appearances (Fig. T38 showed a severe stricture, a hiatus hernia, and con siderable oesophageal dilatation. A high subtotal Polyæ gastrectomy was done. Figs. 14 and 15 show the progress of the condition over a period of six years? This patient refused post-operative dilatation, but hag done well without this.

If high subtotal gastrectomy can give such good results in what appeared to be an almost impassable stricture, why, we may ask, should not vagotomy and gastro-enterostomy, even though perhaps $\frac{5}{3}$ greatly increased cephalic phase of gastric secretion. is not present, give as good or better results ? The author has used this operation, with encouraging results, in severe peptic oesophagitis without stricture but with hiatus hernia (Case 3 ), and in peptic stricture with hiatus hernia (Case 4 ).

CASE 3.-Mrs. B. M., aged 74.

For 20 years this patient had complained of heartburrf and, for some months, of dysphagia. Her haemoglobin was 7.4 g. $\%(50 \%)$, and oesophagoscopy showed of severe haemorrhagic oesophagitis. Barium-meal exami nation revealed a hiatus hernia, without signs of oesopha $-\omega$ geal narrowing. In October I 959 bilateral selective vagotomy was performed, with gastro-enterostomy anso repair of the hiatus hernia from below the diaphragm Since that time the patient has remained well and hef? haemoglobin in June 1960 was $93 \%$. Cine-radiography shows no reflux and no recurrence of the hernia. 


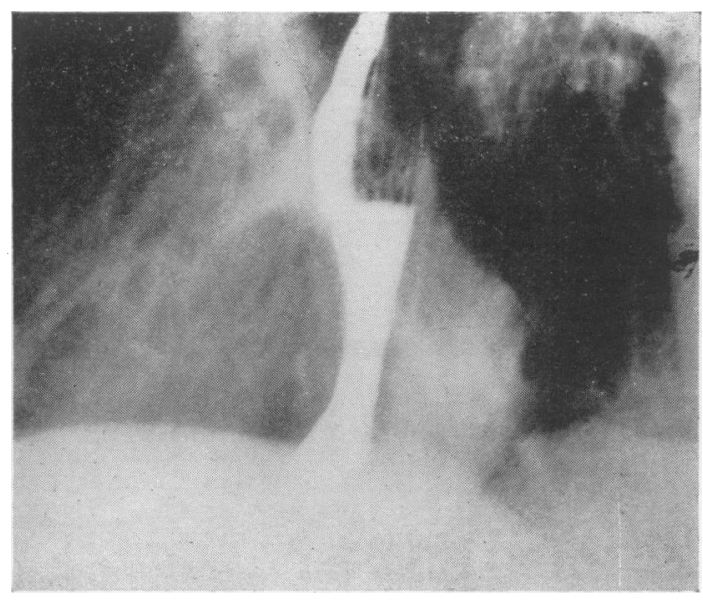

FIG. 15

CASE 4.-Mrs. H. P., aged 75 .

Since 1957 this patient had not eaten solid food because of an early oesophageal stricture due to peptic oesophagitis. She had lost I st. in weight. X-ray examination showed a hiatus hernia with early oesophageal narrowing. In July I959 subdiaphragmatic selective vagotomy was done, with repair of the hernia. Soon after the operation she was able to eat solid food, and remains symptom-free.

Perhaps before many years have passed the true place of vagal section in these conditions will have been settled. We must hope that careful records will be followed by publications.

\section{Peptic Ulcer of Endocrine Origin}

Throughout the long history of gastrectomy for duodenal ulceration it has been known that sometimes repeated haemorrhage, or recurrence of stomal ulcer, could follow two or three gastrectomies in the same patient, until total gastrectomy, with the abolition of all acid-forming cells, was done. The cause of this curious state of affairs remained obscure until Zollinger and Ellison ${ }^{21}$ published their important paper on 'Primary Peptic Ulcerations of the Jejunum Associated with Islet Cell Tumours of the Pancreas'. In this paper they described two cases of jejunal ulcer associated with hyperacidity, in each case after two gastric resections and bilateral vagotomy. It is now known that unless the offending tumour can be found and excised, total gastrectomy is needed to cure this condition Gregory et al. ${ }^{12}$ have recently isolated from such a tumour a substance with chemical and physiological properties resembling the antral hormone, gastrin. Sometimes these tumours cause longstanding diarrhoea before the syndrome declares itself by peptic ulceration. Probably in the future a good deal more will be known about endocrine causes of certain types of ulceration.

\section{CASE 5.-D. S., male, aged 39.}

This patient perforated a duodenal ulcer in 1958 . Later, a subtotal gastrectomy was performed for recurrent ulceration, and this was followed by a second gastrectomy for jejunal ulcer. Bilateral vagotomy was next done for further jejunal ulceration, but this failed to cure the lesion and the gastric acid remained high. At subsequent operation a mass was found in the neck of the pancreas. The high subtotal was converted into a total gastrectomy. Since then the patient has returned to his duties as an army officer.

\section{Perforated Peptic Ulcer}

The management of perforated peptic ulcer has changed little in its long history. Two aspects of this condition are as important today as they ever were-to close the hole and to clean out the peritoneal cavity, especially the subdiaphragmatic spaces. To fail to do these things is to invite subphrenic abscess formation, and antibiotics are never a good answer to a problem when basic surgical principles have been broken The conservative treatment of perforated ulcer has not found popularity in this country Continuous gastric aspiration is by no means always a satisfactory method of keeping the stomach empty, as any surgeon knows who has tried to obtain 12hourly gastric acid by continuous suction. Also, gastric suction does not stop leakage of duodenal juice with bile and pancreatic secretion through a duodenal perforation.

The use of immediate gastrectomy in cases of perforated peptic ulcer, when the history of ulceration is long and when disability has been severe over some years, is sound, and the operation is a good and safe one. However, if in these circumstances the perforation is duodenal, it may be sutured and, at the same time, bilateral selective vagotomy performed with gastro-enterostomy. The electrical stimulation test may be used to demonstrate completeness of nerve section. The only theoretical objection to this operation is the possibility of infection taking place in the extraperitoneal tissues around the oesophagus, and resulting in mediastinitis. In practice this does not seem to happen, and it appears probable that this procedure will replace emergency gastrectomy when a curative operation is undertaken at the time of perforation. Pierandozzi et al. ${ }^{17}$ have reported a series of 75 cases of perforated duodenal ulcer treated at the time of perforation by vagotomy and pyloroplasty. The mortality was $1.3 \%$, and in no case was the operation complicated by mediastinitis or subphrenic abscess. Immediate gastrectomy may be used in perforated gastric ulcer, and careful consideration must be given to the possibility that such ulcers may be neoplastic. 


\section{Massive Haemorrhage}

Nothing new seems to have been added to the surgical treatment of this condition for many years, and many problems still exist in connection with it which are difficult to solve. In Britain, now that almost all our longstanding ulcers are treated by surgical means, massive haemorrhage is becoming a more rare occurrence in our wards Emergency barium meal examination, if the patient is not too seriously ill, done immediately on admission to hospital, is an investigation not used widely enough. If these patients can take food from the start, then they can take barium, and if the examination is undertaken gently, on a tilting table, it seems to be without risk. Often the diagnosis may be obtained at once, and the patient then receives the usual medical management. If continued or repeated bleeding calls for surgical treatment, the surgeon is happy to know, before he starts, the cause of the haemorrhage

CASE 6.- - F. F., male, aged 7I.

This man was admitted to hospital with haematemesis. On admission his haemoglobin was $25 \%$. After a blood transfusion a modified emergency barium meal was carried out with the patient tilted a little on the X-ray table. A filling defect was found close to the cardiac opening. The X-ray appearance had all the features of a simple growth. Because the patient continued to bleed, gastrostomy was performed and a simple myoma removed.

The problem of massive bleeding when no lesion can be demonstrated before operation, and perhaps when there is no history of dyspepsia, is still with us. When the surgeon is confronted with the situation at operation, if he rubs the surface of the stomach and duodenum with a swab he may bring up multiple petechial haemorrhages over the lesion. Most surgeons experienced in this work have probably excised that lesion which consists of almost nothing more than a single vessel sticking up through a virtually normal mucosa. This lesion is often palpable with the finger from within the stomach or duodenum as a small, firm, seedlike swelling. For this reason, if the surgeon cannot demonstrate a lesion at operation, he should open the stomach and inspect and palpate the gastric wall and pass a finger into the duodenum, for a blind gastrectomy may leave such a lesion in position, and death may follow from further haemorrhage. Shallow, soft ulcers are often quite impalpable, but when rubbed with a swab these will probably always show the petechial haemorrhages on the peritoneal coat.

Vagotomy and gastro-enterostomy, with suture of a bleeding duodenal ulcer, is gaining favour in some places, but would seem to be not without risk. If the patient stops bleeding for a few days, it would seem reasonable to perform vagotomy with drainage without delay, but to try to make vagotomy deal with a bleeding point seems to be asking almost too much, unless suture of the perforation can be relied upon to deal adequately. with the bleeding vessel.

CASE 7.-A. C., male, aged 58.

This patient presented with massive haemorrhage with melaena and some haematemesis. Because of repeated bleeding under medical care, it was decideg that emergency operation should be undertaken. Thes was a seven-year history of recurrent epigastric paim relieved by food. At operation no obvious lesion was found, but it was felt that possibly a small ulcer was present in the superior aspect of the duodenum jusit. beyond the pylorus. The right gastric artery was ligated and a bilateral vagotomy performed, with gastrog enterostomy. Completeness of nerve section was demonstrated by the electrical stimulation test. $\mathrm{Be}$ cause the ulcer was not quite proved no attempt was. made to open the duodenum and suture the ulce Gastrectomy was not performed because the patienit had had a previous cerebro-vascular accident, and because of his size the duodenal stump was not easy to handle. Following this operation the patient bled again, and further operation was undertaken and 8 gastrectomy performed. From this he made an unevent ful recovery. At operation a shallow ulcer was found in the duodenum just beyond the pylorus. It is im possible to know whether in fact the same result would have been obtained had suture of the ulcer been don from within at the time of the vagotomy. This, hew ever, seems not a very reliable method of guaranteerng no further haemorrhage from the ulcer site.

In so many branches of Medicine progress recent years has been remarkable. Gasto enterology has not been left behind. The greatest advance in the field of peptic ulcer has been some understanding of etiology, based of gastric physiology, and the name of Dragstedt wit always find a place in the history of this subject? REFERENCES

1. BERG, A. A. (1930), Ann. Surg., 92, 340.

2. BURGE, H. (1958),' The Eleventh Alexander Simpson Smith Memorial Lecture,' West London Hospital Medical Schooto London.

3. BURGE, H. (1960), Postgrad. med. $7 ., 36,2$.

4. BURGE, H. (1960), Ann. roy. Coll. Surg. Engl., 26, 231.

5. BURGE, H., and PICK, E. J. (1958), Brit. med.' F., i, 613.

6. BURGE, H., and VANE, J. R. (1958), Ibid., i, 61 5.

7. CARLSON, A. J. (1925), 甹. Amer. med. Ass., 85, 1468.

8. CHALFEN, S. S. (1928), Arch. Verdau.-Kr., 45, 250.

9. DRAGSTEDT, $L$. R., and OWENS, F. M.'(1943), Proc. Sog exp. Biol. (N.Y.), 53, 152 .

10. DRAGSTEDT, L. R., and WOODWARD, E. R. (1951) F. Amer. med. Ass., 145, No. 11,795 .

11. EDKINS, J. S. (1906), Ұ. Physiol. (Lond.), 34, 133.

12. GREGORY, R. A., TRACY, H. J., FRENCH, J. M., an 12. GRERCUS, W. (1960), Lancet, i, ro45.
13. JOHNSON, F. E., and BOYDEN, E. A. (1943), Surg. Gyne?

14. LANDOR, J. 395. (1959), 'The Physiology and Treatment of Peptic Ulcer,' Chicago: University of Chicago Press.

I 5. OBERHELMAN, H. A.,' Jr. (I959), Ibid.
I6. PAVLOV, I. P. (1902), "The Work of the Digestive Glands trans. by W. H. Thompson. London: Chas. Griffin \& Cov

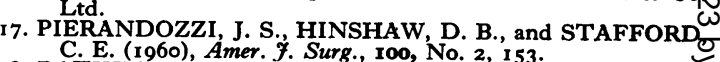
C. E. (1960), Amer. Y. Surg., 100, No. 2, 153.

18. RATKIN, H. F., KIRSNER, J. B., and PALMER, W. L

(1959), f. Amer. med. Ass. 169, 789.
19. STEMPIEN, S. J., and WEINBERG, J. A. (1953), Ibid.థ

20. WANGENSTEEN, O. H., and LEVEN, N. L. (1959), Surg.
Gynec. Obstet., 88, 560 . Gynec. Obstet., 88, 560

21. ZOLLINGER, R. M., and ELLISON, E. H. (1955), Ann Surg., 142, 709. 